\title{
Non-Newtonian Shear-Thinning Fluid Passing Through a Duct with an Obstacle, Using a Power Law Model
}

\author{
Mohammadreza Saffarian 1 - Moona Mohammadi1, ${ }^{*}$ - Mohammadreza Mohammadi2 \\ 1 Shahid Chamran University, Faculty of Mechanical Engineering, Iran \\ 2 Iranian National Gas Company, Bushehr Gas Company, Iran
}

\begin{abstract}
Non-Newtonian fluids have not been frequently considered in different research although they are common fluid type in the industry and environment in comparison to Newtonian fluids. In this paper, a non-Newtonian fluid with a shear-thinning property is considered in a specific geometric condition. The flow is considered to be laminar, and the geometric subject of the research is a rectangular duct with an obstacle, which is assumed to be in the middle of the duct with a height of half the duct width. This research provides a numerical solution using a written MATLAB code with a SIMPLEC algorithm and a power law model. This code is validated by comparing code results with analytical results for a specific condition. The results of this research show variations of velocity and viscosity in the duct, which can be extremely useful in future research and applications, not only because of frequent usage of shear-thinning fluids in industrial applications but also because of the common duct shape facilities in different processes in several industries.
\end{abstract}

Keywords: non-Newtonian fluid, SIMPLEC, internal flow, shear-thinning flow

\author{
Highlights \\ - Using numerical calculation for a non-Newtonian fluid. \\ - The behaviour of shear thinning fluid in a duct shape geometry with one obstacle. \\ - Variation of velocity and viscosity before and after an obstacle for shear-thinning fluids. \\ - $\quad$ Result validation with analytical solution.
}

\section{O INTRODUCTION}

At present, the usage of non-Newtonian fluids is very common in industrial applications. Regarding significant differences between their properties and behaviour with that of Newtonian fluids, various research should be done to understand their behaviour in different conditions.

Computational fluid dynamics (CFD) is a common numerical calculation procedure that have been used in several simulation research studies for different geometries [1] to [7]. Rek et al. [1] used CFD simulation to analyse a heating oven. Lupse et al. [2] worked on an URANS simulation of flow for square cylinder geometry. Liao et al. [3] used CFD to simulate the flow in a directional valve. Vosoughifar et al. [4] worked on fluid flow over stepped spillways. Ravnik et al. [5] proposed a numerical model for particle movement in cellular flow. Ternik and Rudolf [6] considered a heated circular cylinder numerically. Herakovič et al. [7] proposed a fluid model for flow force reduction and used the Ansys CFX CFD simulation tool for their work.

Despite using CFD in all this and other similar research, different methods of CFD were mostly used in different conditions or industrial applications while for none of them was the fluid assumed to be nonNewtonian.
In contrast, non-Newtonian fluids were studied by several other researchers using two main approaches. In the first approach, a case study industrial application was considered [8] to [12]. Speetjens et al. [8] studied non-Newtonian fluid flow in industrial in-line mixers. Haun et al. [9] derived a lubrication equation for a nonNewtonian thin film. Marn et al. [10] had a biological focus on working with aortic valves. Petrun et al. [11] engaged various viscosity parameters in a modified elasto-plastic friction model and discussed their effect on the final friction force-torque, transmitted through the contact of the friction clutch. Another example of application of non-Newtonian fluids is in the drilling industry, studied by Safaiy et al. [12].

Although this approach follows an industrial case study, in the second approach a basic study has been developed that can be useful in several industrial applications [13] to [21]. Safaei et al. [13] and Ternik and Rudolf [14] considered heat transfer convection in a determined geometry with a specific non-Newtonian fluid. Ntamba and Fester [15] worked on short square-edged orifice plates to determine pressure losses. Ashhab et al. [16] studied blood flow as a non-Newtonian fluid and selected microchannels as the problem geometry using FLUENT to solve the CFD procedure. Similarly, Bandyopadhyay and Das [17] used CFD and FLUENT for solving a procedure; however, they worked with an elbow 
shape to investigate non-Newtonian and gas nonNewtonian liquid flow. Shahmardan et al. [18] worked on a channel with a cavity shape. Norouzi et al. [19] used an analytical solution in a curved rectangular duct for a creeping dean flow of Bingham plastic. Other examples of non-Newtonian fluid research are Maghmoumi et al. [20] Yao and Molla [21], both working on flat plates.

The current research follows a numerical solution for a non-Newtonian fluid passing a duct, which is generally the same method of all the aforementioned research. The main approach of this research can be determined as basic research [13] and [21] using power law [10], [17] and [21] as the solution method. The problem geometry has some similarities with [8] and [19], and shear-thinning fluid was considered in [21]. Despite all these similarities, the unique geometry of this research in which a plane is placed in the middle of the duct and the size of the plane is half the height of the duct width had not previously been considered, while the final results of this paper lead to an illustration of the velocity profile and the viscosity variation in different values of index $\mathrm{n}$ for a shearthinning fluid.

\section{MATERIAL AND METHOD}

Newtonian fluid behaviour passing an obstacle can be dramatically different from that of a non-Newtonian fluid. In a Newtonian fluid, viscosity is constant, so velocity distribution will be obtained from a constant viscosity, while in a non-Newtonian fluid viscosity is variable and is dependent on different velocity gradients in the flow field.

According to fluid type, a non-Newtonian fluid can be considered by different mathematical models, such as power law, which are applicable for shearthinning and shear-thickening fluid. In this model, the tension value and fluid shear rate can be defined as Eqs. (1) and (2) [22].

$$
\begin{gathered}
\tau_{y x}=m \dot{\gamma}_{y x}^{n} \\
\mu=m \dot{\gamma}^{n-1}
\end{gathered}
$$

where $m$ and $n$ are power coefficients and $\tau_{y x}, \dot{\gamma}_{y x}$ and $\mu$ are shear stress, shear rate and viscosity, respectively. The $n$ value in these two fluid type is defined as follows.

$$
\begin{array}{ll}
\text { Shear thinning } & n<1, \\
\text { Shear thickening } & n>1 .
\end{array}
$$

In this research, a MATLAB code is used for calculations based on the SIMPLEC method to obtain velocity distribution, while flow is considered to be laminar.

Three different grid networks were considered to show network independence. Considering $21 \times 83$ grid, $25 \times 100$ grid and $31 \times 125$ grid, it was deduced that velocity has very little difference in these grids. Thus, a $25 \times 100$ grid is used in calculations due to a reduced calculation time with the same accuracy. Table 1 shows mesh independence in considered grids.

Table 1. Mesh number and average of lateral velocity results

\begin{tabular}{lccc}
\hline Mesh Number & $21 \times 83$ & $25 \times 100$ & $31 \times 125$ \\
\hline $\begin{array}{l}\text { Average of lateral velocity } \\
\text { above obstacle [m/s] }\end{array}$ & $0 / 967744$ & $0 / 976555$ & $0 / 981629$ \\
\hline
\end{tabular}

\subsection{Mathematical Method}

While Navier-Stocks equations are applicable in Newtonian fluids, in non-Newtonian fluids Cauchy equations are used. The governing equations in steady, 2-dimentional and isotherm conditions are as follows [23]:

$$
\frac{\partial V_{x}}{\partial x}+\frac{\partial V_{y}}{\partial y}=0
$$

$$
\begin{aligned}
& \rho\left[V_{x} \frac{\partial V_{x}}{\partial x}+V_{y} \frac{\partial V_{x}}{\partial y}\right]=-\frac{\partial P}{\partial x}+\frac{\partial \tau_{x x}}{\partial x}+\frac{\partial \tau_{x y}}{\partial y}, \\
& \rho\left[V_{x} \frac{\partial V_{y}}{\partial x}+V_{y} \frac{\partial V_{y}}{\partial y}\right]=-\frac{\partial P}{\partial y}+\frac{\partial \tau_{y x}}{\partial x}+\frac{\partial \tau_{y y}}{\partial y} .
\end{aligned}
$$

Unlike Newtonian fluid, the relation between the tension and shear rate in non-Newtonian fluid is nonlinear.

As mentioned before, the Cauchy momentum in non-Newtonian fluids is the governing equation, but Navier-Stocks equations can be used in numerical solutions if in every grid viscosity assumed to be constant and viscosity variation assumed to be variable in all the field.

The calculated viscosity in Eq. (1) is a scalar value due to the use of rheometer and shear rate, while viscosity and shear rate is a tensor so it is necessary to use the average $\dot{\gamma}$ for viscosity calculation.

For solving this problem, the average shear rate value is used. This value, which is called the extended shear rate, is defined as follows [18]:

$$
\overline{\bar{\gamma}}: \overline{\bar{\gamma}}=\sum_{i} \sum_{j} \dot{\gamma}_{i j} \dot{\gamma}_{j i}
$$


In Eq. (8), the shear rate value is calculated according to Eq. (9) [18]:

$$
\begin{aligned}
\dot{\gamma} & =\left\{2\left[\left(\frac{\partial V_{x}}{\partial x}\right)^{2}+\left(\frac{\partial V_{y}}{\partial y}\right)^{2}+\left(\frac{\partial V_{z}}{\partial z}\right)^{2}\right]+\left(\frac{\partial V_{x}}{\partial x}+\frac{\partial V_{y}}{\partial y}\right)^{2}+\right. \\
& \left.+\left(\frac{\partial V_{x}}{\partial x}+\frac{\partial V_{z}}{\partial z}\right)^{2}+\left(\frac{\partial V_{y}}{\partial y}+\frac{\partial V_{z}}{\partial z}\right)^{2}\right\}^{0.5} .
\end{aligned}
$$

For this calculation, it is necessary to estimate the field velocity as the first step; after calculating $\dot{\gamma}$ from Eq. (9), viscosity would be calculated via Eq. (1) and is substituted in Eq. (10).

$$
\mu=0.9 \mu_{\text {old }}+0.1 \mu_{\text {new }} .
$$

The value of $\mu_{\text {old }}$ can be assumed to be a Newtonian fluid viscosity. The value of $\mu_{\text {new }}$ is calculated value from Eq. (1).

Because the flow is assumed to be laminar, it is necessary to calculate critical Reynolds number to determine maximum velocity in which the flow in the duct remains laminar. Eq. (11) shows how to calculate critical Reynolds [22].

$$
\operatorname{Re}_{M R_{c}}=\frac{6464 n}{(3 n+1)^{2}}(2+n)^{(2+n) / 1+n}
$$

In Eq. (11) $\operatorname{Re}_{M R_{c}}$ is critical Reynolds and $n$ is index number of non-Newtonian fluid.

Substituting obtained critical Reynolds from Eq. (11), critical velocity will be obtained from Eq. (12). The value of diameter $(D)$ in Eq. (12) is calculated based on the hydraulic diameter. Because the considered problem is a duct, the hydraulic diameter will be obtained from Eq. (13) [8].

$$
\begin{gathered}
\operatorname{Re}_{P L}=\frac{\rho V^{2-n} D^{n}}{8^{n-1} m\left(\frac{3 n+1}{4 n}\right)^{n},} \\
D_{h}=\frac{4 A}{P}=\frac{4 a b}{2(a+b)}=\frac{2 a b}{(a+b)} .
\end{gathered}
$$

In this equation, $a$ and $b$ are the width and height of the considered section.

As previously mentioned, the equation under consideration is solved based on the SIMPLEC method. To avoid divergence, a velocity matrix is divided into internal and external sections and is assumed to be zero in the boundary. The entrance boundary is separated from calculated values and is applied as a boundary condition of this matrix. The upwind method and staggered grid are used for discretization. Fig. 1 shows how to determine grids in this mesh generation. Pressure and velocity coefficients in the numerical solution are 0.3 and 0.5 respectively [24].

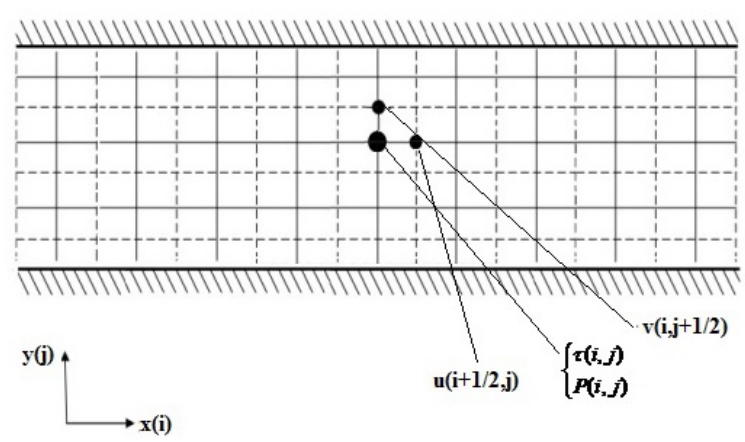

Fig. 1. Velocity and pressure node in staggered grid

\section{RESULTS AND DISCUSSION}

In this research, a duct with the length of $1 \mathrm{~m}$ and the height of $25 \mathrm{~cm}$ is considered. As previously mentioned, the selected grid network is $25 \times 100$ in the $y \times x$ plane. The duct has an obstacle in the middle, as shown in Fig. 2. Velocities on the wall are assumed to be zero and assumed to be a certain value in the entrance boundary in the program.

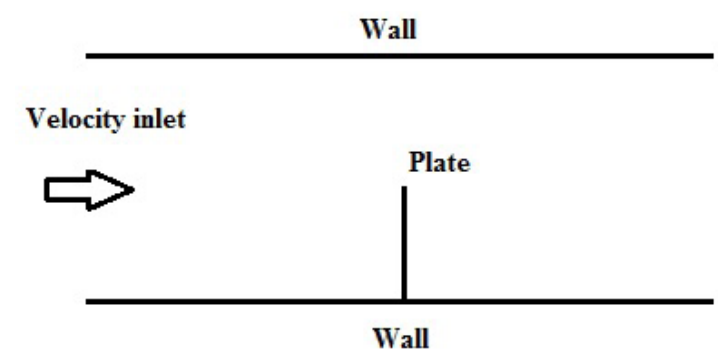

Fig. 2. Schematic of duct

Numerical solution validation can be performed by comparing the results with experimental, analytical solutions or previously validated numerical solutions. Shahmardan et al. [18] compared their results with an analytical solution, while a Newtonian fluid was used in the validation section. Similarly, in this paper, the same method was used and the results of numerical solution code were compared with an analytical solution for a Newtonian fluid. For the purpose of validation, the code was applied on a duct with no obstacle in the middle using a Newtonian fluid as a passing fluid. Table 2 shows the results of calculated velocity values in different Reynolds numbers while the analytical result in the considered point is $1 \mathrm{~m} / \mathrm{s}$.

In this research, four different fluids with different values of $m$ and $n$ have been considered. 
Table 3 shows fluid properties and critical Reynolds in each considered fluid. According to the properties of each fluid, critical Reynolds will be calculated according to Eq. (11). To make the results of different fluids comparable, an equal Reynolds number (150) was used.

Table 2. Calculated velocities in different Reynolds numbers

\begin{tabular}{cc}
\hline Calculated numerical velocity & Reynolds number \\
\hline 0.9930 & 800 \\
\hline 0.9949 & 900 \\
\hline 1.0013 & 1000 \\
\hline 1.0000 & 1100 \\
\hline
\end{tabular}

Table 3. Properties of four selected fluids [22]

\begin{tabular}{cccc}
\hline$n$ & $m$ & $\rho\left[\mathrm{kg} / \mathrm{m}^{3}\right]$ & $\mathrm{Re}_{c r}$ \\
\hline 0.5 & 12 & 1130 & 2381.46 \\
\hline 0.68 & 0.4 & 1000 & 2292.13 \\
\hline 0.3 & 9.6 & 1090 & 2344.74 \\
\hline 0.41 & 2.6 & 1225 & 2422.65 \\
\hline
\end{tabular}

Fig. 3 shows viscosity variation in Reynolds number 150 in different $n$ values. This figure demonstrates that at the place of the obstacle, a huge variation in viscosity occurs and there is a dramatic drop before the obstacle and a sharp increase after that. The amount of this drop in $n=0.5$ is higher than other values of $n$.

When all properties, such as $m$ and density, are engaged, the viscosity variation does not have a certain order.

For determining the effect of $n$, viscosity is calculated in a specific condition in which density and the $m$ value are equal and just $n$ changes. This condition is shown in Fig. 4, which illustrates that the increasing value of $n$ will result in an increase in viscosity.

Lateral velocity passing on the obstacle in different $\mathrm{n}$ numbers is shown in Figs. 5 and 6. These figures illustrate that fluid velocity passing on the obstacle would have sudden changes because of constant value of velocity and cross sectional area changing, and that in nodes beside the obstacle a sharp increase would happen.

Figs. 7 and 8 demonstrate velocity variations in the duct, which have a significant variation above the obstacle; in $n=0.68$, the velocity increase is at maximum; for $n$ values of $0.41,0.3$ and 0.5 , the velocity increase is decreasing, respectively.

Regarding Fig. 3, these variations are exactly the opposite of the variation of viscosity passing the

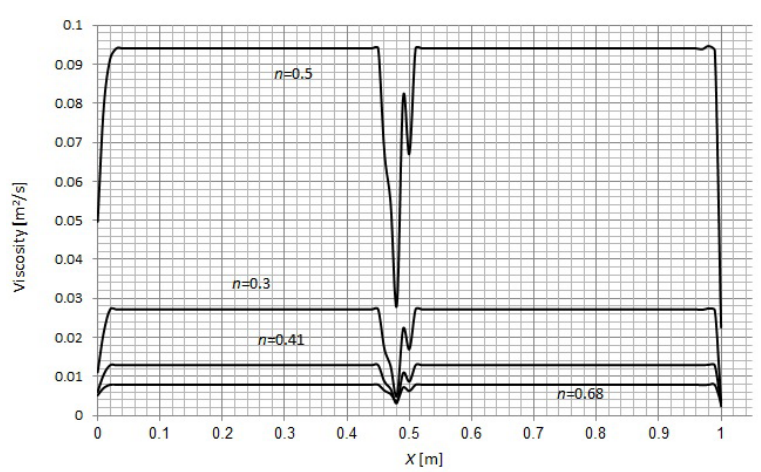

Fig. 3. Viscosity variations in axial direction, $R e=150$

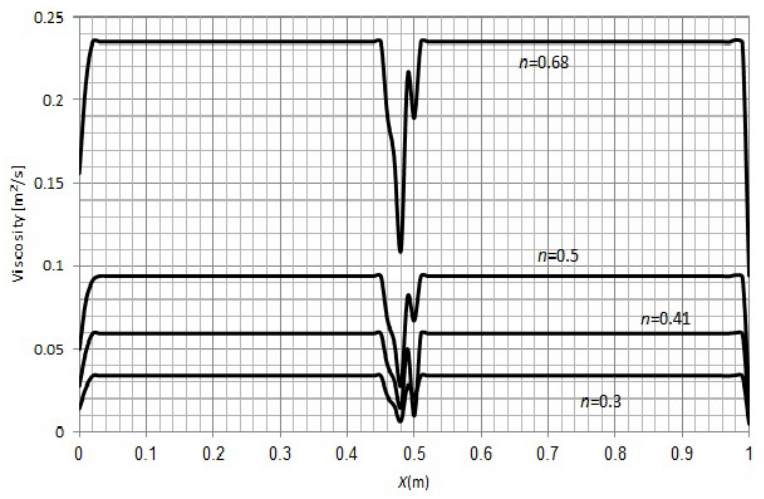

Fig. 4. Comparison of 4 different hypothetical $n$ index, $R e=150, \rho=1130 \mathrm{~kg} / \mathrm{m}^{3}, m=12$

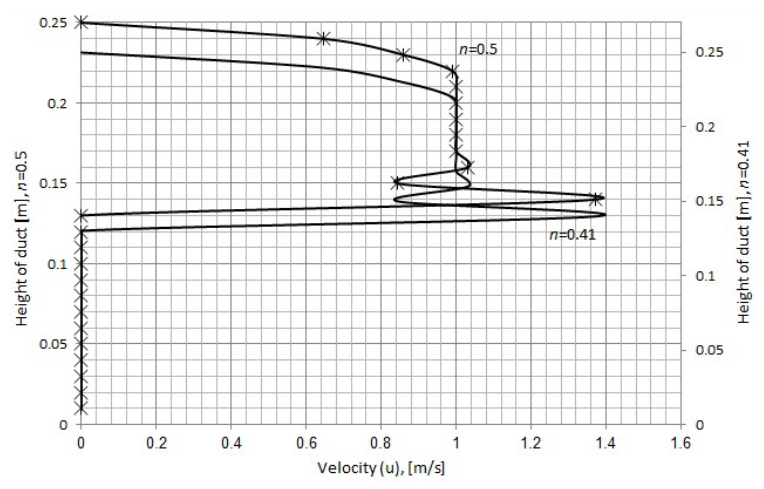

Fig. 5. Lateral velocity passing in obstacle in different $n$ number, $R e=150$

obstacle. In other words, regarding low viscosity, fluid resistance against the movement is less.

Figs. 9 to 12 illustrate variation of the lateral velocity before and after the obstacle in $4 n$ values. According to these figures, before the obstacle velocity is increased and after that the velocity is decreased. In three values of $n, 0.68,0.5$ and 0.3 , the velocity increase is similar but in $n=0.41$ the velocity increase is less due to the higher density in the fluid. 


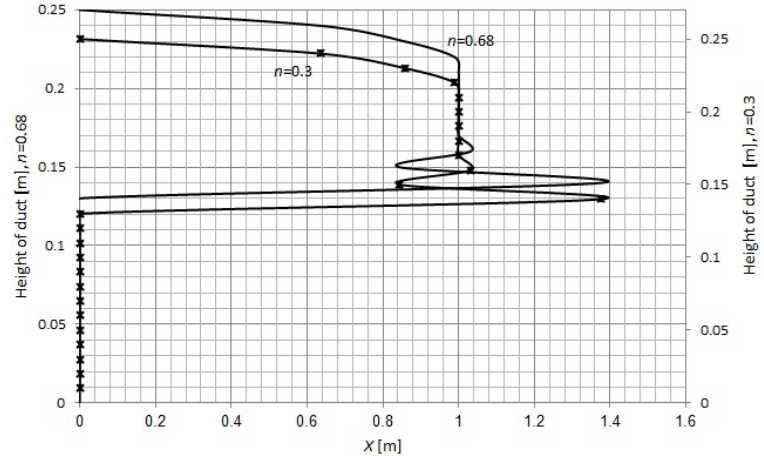

Fig. 6. Lateral velocity passing in obstacle in different $n$ number, $R e=150$

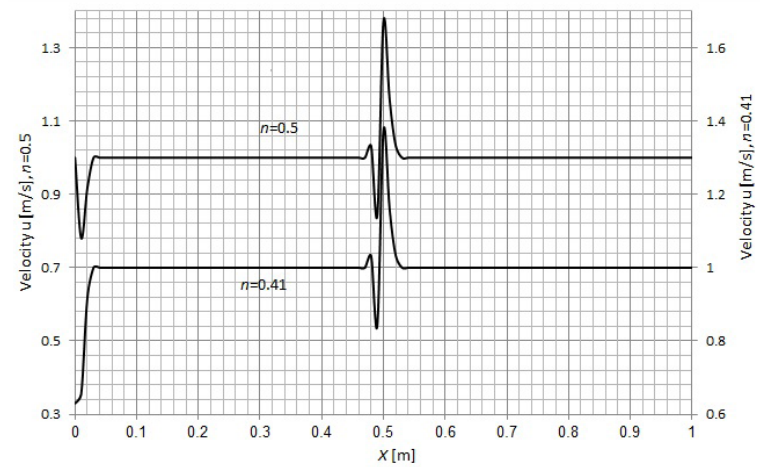

Fig. 7. Velocity variations in axial direction, $R e=150$

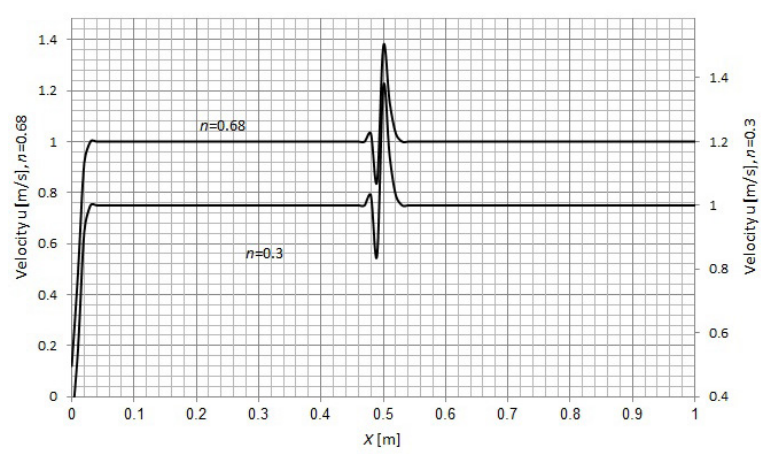

Fig. 8. Velocity variations in axial direction, $R e=150$

It can be deduced that velocity increase is related to viscosity decrease, and the velocity decrease is dependent on viscosity increase.

\section{CONCLUSION}

In this paper, non-Newtonian shear-thinning fluid in a duct passing an obstacle is considered and four values of $\mathrm{n}$ are used.

The results of this research show that in constant fluid properties the increase in value of $n$ will also

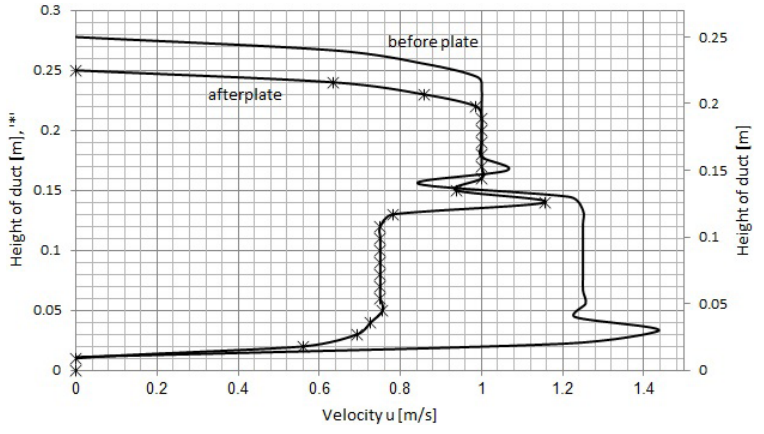

Fig. 9. Velocity variations in lateral direction before and after obstacle, $R e=150, n=0.68$

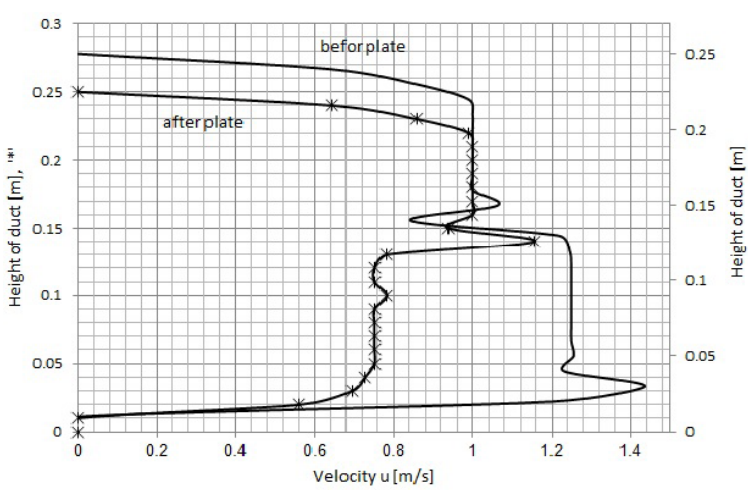

Fig. 10. Velocity variations in lateral direction before and after obstacle, $R e=150, n=0.5$

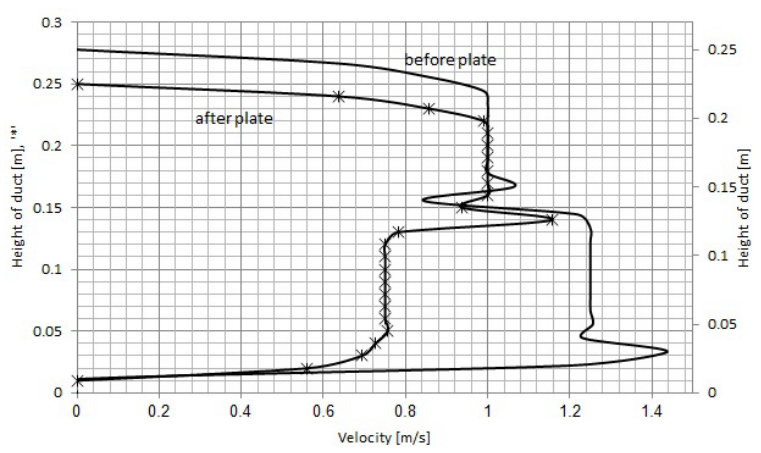

Fig. 11. Velocity variations in lateral direction before and after obstacle, $R e=150, n=0.3$

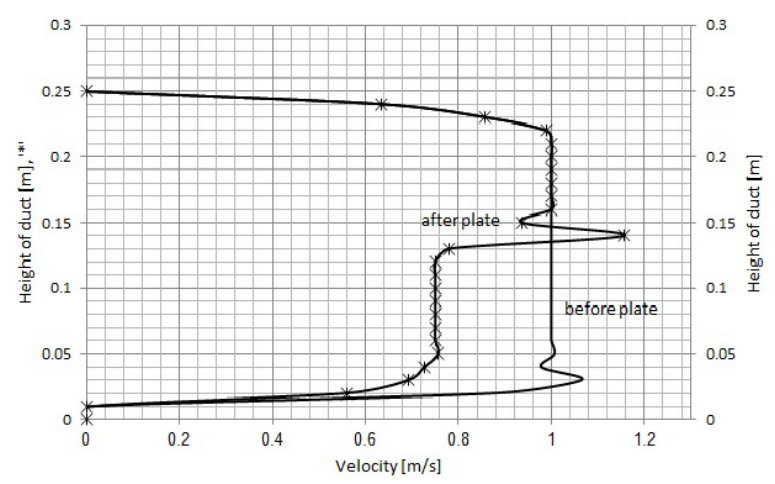

Fig. 12. Velocity variations in lateral direction before and after obstacle, $R e=150, n=0.41$ 
cause an increase in viscosity. Velocity variation in the duct has an opposite relation with viscosity; in the minimum value of viscosity, the velocity would be maximum due to low fluid resistance against the flow movement. Because of rapid changes in the cross-sectional area in the flow passing the obstacle, velocity has a significant increase in nodes near the plate.

The results of this research revealed a huge decline before the obstacle and a significant rise after that, while the amount of this drop in $n=0.5$ is higher than other values of $n$. The results also showed similarities between three values of $n, 0.68,0.5$ and 0.3 , in velocity increase while, at $n=0.41$ the velocity increase is less due to the higher density in the fluid.

This paper finally provided the variation of velocity and viscosity and their dependence on fluid properties in a specific geometry. Although some similarities can be found in the geometrical aspects in previous research in which the duct shape was considered, this paper focused on the effect of a plate in the middle of the duct on velocity and viscosity variations. The other major finding of this paper is the fluid type assumption (i.e. shear thinning), which had not frequently been considered in previous research and had been never studied in such a geometry before.

\section{NOMENCLATURE}

$\begin{array}{ll}m & \text { Power coefficient }[-] \\ n & \text { Power coefficient }[-] \\ \tau & \text { Shear stress }\left[\mathrm{kg} / \mathrm{m} \cdot \mathrm{s}^{2}\right] \\ \tau_{i j} & \text { Shear stress in } i, j \text { plane }\left[\mathrm{kg} / \mathrm{m}^{2} \mathrm{~s}^{2}\right] \\ \dot{\gamma} & \text { Shear rate }\left[\mathrm{s}^{-1}\right] \\ \dot{\gamma}_{i j} & \text { Shear rate in i,j plane }\left[\mathrm{s}^{-1}\right] \\ \mu & \text { Viscosity }\left[\mathrm{m}^{2} / \mathrm{s}\right] \\ V & \text { Velocity }[\mathrm{m} / \mathrm{s}] \\ V_{i} & \text { Velocity in } i \text { direction }[\mathrm{m} / \mathrm{s}] \\ P & \text { Pressure }\left[\mathrm{kg} / \mathrm{m} \cdot \mathrm{s}^{2}\right] \\ \rho & \text { Density }\left[\mathrm{kg} / \mathrm{m}^{3}\right] \\ \operatorname{Re} & \text { Reynolds number } \\ \operatorname{Re}{ }_{M R_{c}} & \text { Critical Reynolds } \\ D & \text { Diameter }[\mathrm{m}]\end{array}$

\section{REFERENCES}

[1] Rek, Z., Rudolf, M., Zun, I. (2012). Application of CFD simulation in the development of new generation heationg oven. Strojniški vestnik - Journal of Mechanical Engineering, vol. 58, no. 2, p. 134-144, D0l:10.5545/sv-jme.2011.163

[2] Lupse, J., Skerget, L., Ravnik, J. (2015). BEM-based algorithm for URANS simulation of flow over a square cylinder. Strojniški vestnik - Journal of Mechanical Engineering, vol. 61, no. 4, p. 254-264, DOI:10.5545/sv-jme.2014.2185.

[3] Liao, Y., Yuan, H., Lian, Z., Feng, J., Guo, Y. (2015). Research and analysis of hysteresis characteristics of a large flow directional valve. Strojniški vestnik - Journal of Mechanical Engineering, vol. 61, no. 6, p. 355-364, D0l:10.5545/svjme.2015.2487.

[4] Vosoughifar, H., Dolatshah, A., Shokouhi, S., Nezhad, S. (2013). Evaluation of fluid flow over stepped spilleays using the finite volume method as a novel approach. Strojniški vestnik - Journal of Mechanical Engineering, vol. 59, no. 5, p. 301-310, DOI:10.5545/sv-jme.2012.669.

[5] Ravnik, J., Hribersek, M., Vogel, F., Steinmann, P. (2014). Numerical simulation of particle movement in cellular flows under the influence of magnetic forces. International Journal of Simulation Modelling, vol. 13, no. 3, p. 312-322, D0I:10.2507/IJSIMM13(3)4.268.

[6] Ternik, P., Rudolf, R. (2014). Laminar forced convection heat transfer. International Journal of Simulation Modelling, vol. 13, no. 3, p. 312-322, D0I:10.2507/IJSIMM13(3)5.271.

[7] Herakovič, N., Duhovnik, J., Šimic, M. (2015). CFD simulation of flow force reduction in hydraulic valves. Tehnički vjesnik Technical Gazette, vol. 22, no. 2, p. 453-463, Dol:10.17559/ TV-20141128090939.

[8] Speetjens, M., Rudman, M., Metcalfe, G. (2006). Flow Regime Analysis of Non-Newtonian Duct Flow. Physics of Fluids, vol. 18, no. 1, p. 013101-1/14, D0l:10.1063/1.2163913.

[9] Huan, J., Zhang, L. (2006). A variational approach to the establishment of a lubrication equation for a non-Newtonian thin film. Strojniški vestnik - Journal of Mechanical Engineering, vol. 52, no. 9, p. 587-591.

[10] Marn, J., Iljaz, J., Zonic, Z., Ternik, P. (2012). Non-Newtonian blood flow around healthy and regurgitated aortic valve with coronary blood flow involved. Strojniški vestnik - Journal of Mechanical Engineering, vol. 58, no. 7-8, p. 482-491, DOl:10.5545/sv-jme.2010.023.

[11] Petrun, T., Flasker, J., Kegl, M. (2013). A theoretical and numerical study of an additional viscosity term in a modified elasto-plastic friction model for wet friction clutch simulation. Strojniški vestnik - Journal of Mechanical Engineering, vol. 59, no. 6, p. 358-366, Dol:10.5545/sv-jme.2012.920.

[12] Safaiy, M., Maghmoumi, Y., Karimipour, A. (2012). Numerical investigation of turbulence mixed convection heat transfer ofwater and drilling mud inside a square enclosure by finite volume method. The $4^{\text {th }}$ International Meeting of Advances in Thermofluids, vol. 1440, no. 1, AIP Publishing, DOl:10.1063/1.4704283.

[13] Safaei, M., Rahmanian, B., Goodarzi, M. (2011). Numerical study of laminar mixed convection heat transfer of power-law. International Journal of Physical Sciences, vol. 6, no. 33, p. 7456-7470, DOl:10.5897/IJPS11.1092.

[14] Ternik, P., Rudolf, R. (2013). Laminar natural convection of non-Newtonian nanofluids in a square enclosure with differentially heated side walls. International Journal of Simulation Modelling, vol. 12, no. 1, p. 5-16, D0l:10.2507/ IJSIMM12(1)1.215.

[15] Ntamba, B., Fester, V. (2012). Pressure losses and limiting Reynolds numbers for non-Newtonian fluids in short square- 
edged orifice plates. Journal of Fluids Engineering, vol. 134 no. 9, p. 091204-091204-9, D0l:10.1115/1.4007156.

[16] Ashhab, M., Al-Salaymeh, A., Al-Muhtaseb, A., Al-Muhtaseb, M. (2012). Hershel- Bulkley Blood Flow in Rectangular Microchannels. International Journal of Research and Reviews in Applied Sciences, vol. 10, no. 1, p. 23-29.

[17] Bandyopadhyay, T., Das, S. (2013). Non-Newtonian liquid flow through elbows- CFD analysis. Journal Applied Fluid Mechanics, vol. 6, no. 1, p. 131-141.

[18] Shahmardan, M., Norouzi, M., Naghikhani, A. (2014). Numerical simulation of non-Newtonian Fluid through a channel with a cavity. Modares Mechanical Engineering, vol. 14, no. 6. p. 35-40. (In Persian)

[19] Norouzi, M., Vamerzani, B., Davoodi, M., Biglari, N., Shahmardan, M. (2015). An exact analytical solution for creeping dean flow of Bingham plastics through curved rectangular ducts. Rheologica Acta, vol. 54, no. 5, p. 391-402, DOI:10.1007/s00397-014-0807-x.
[20] Maghmoumi, Y., AbolHasan Alavi, S., Safaei, M., Nourollahi, I. (2008). Numerical analyses of steady non-Newtonian flow over flat plate on intermediate Reynolds Numbers by finite volume method. International Journal of Advanced Design and Manufacturing Technology, vol. 1, no. 4, p. 21-31.

[21] Yao, L., Molla, M. (2007). The boundary layer of a nonNewtonian fluid on a flat plate with a uniform heat flux. Journal of Heat Transfer, vol. 131, no. 1, p. 011702-011708, DOI:10.1115/1.2977610.

[22] Chabbra, R., Richarson, J. (2008). Non Newtonian Flow and Applied Rheology, Elsevier, Amsterdam.

[23] Irgens, F. (2014). Rheology and Non-Newtonian Fluids. Springer International Publishing, Heidelberg, D0I:10.1007/978-3-31901053-3.

[24] Patankar, S. (1990). Numerical Heat Transfer and Fluid Flow. Mc Graw Hill Book Company, New York. 